\title{
Factors governing human fear of wolves: moderating effects of geographical location and standpoint on protected nature
}

\author{
Maria Johansson $^{1} \cdot$ Camilla Sandström $^{2} \cdot$ Eja Pedersen $^{1} \cdot$ Göran Ericsson $^{3}$
}

Received: 13 November 2015 /Revised: 29 July 2016 / Accepted: 21 September 2016 /Published online: 20 October 2016

(C) The Author(s) 2016. This article is published with open access at Springerlink.com

\begin{abstract}
This study analyses psychological antecedents of feelings of fear of wolves in a proportional sample of the Swedish population (national sample, $n=545$ ) and in a sample of people in counties with wolf presence (regional sample, $n=1,892$ ). Structural equation modelling of survey data suggests a dual pathway to selfreported fear. One path encompasses the appraisal of the environmental context operationalised as a potential wolf encounter. The second path concerns the appraisal of the social context assessed as social trust in managing authorities. The relative importance of the paths differs between the national and the regional sample, and between people in the administrative centre of the region and the regional periphery. We show that the public's fear of wolves should be addressed both at an individual level, focusing on situations with potential encounters, and at a collective level, by strengthening the trust between the public and authorities, and regional variation should be considered.
\end{abstract}

Keywords Fear · Appraisal · Trust · Wolves

Maria Johansson

maria.johansson@mpe.lth.se

1 Department of Architecture and the Built Environment, Environmental Psychology, Lund University, Box 118, 221 00 Lund, Sweden

2 Department of Political Science, Umeå University, Umeå, Sweden

3 Department of Wildlife, Fish and Environmental Studies, Swedish University of Agricultural Sciences, Uppsala, Sweden

\section{Introduction}

Today, in many places, wolves are increasing in numbers and range and returning to previous areas where they were once exterminated. This change in nature is the direct result of environmental policy change, including systematic efforts to restore wolf populations, based on the idea that wolves and other large carnivores play a pivotal role in ecosystems. The presence of wolves and other large carnivores is assumed to enhance biodiversity and control ecosystem functioning, and thus, benefit human livelihoods and well-being (Dressel et al. 2014; Boitani and Linell 2016). The presence and management of wolves is, however, subject to diverging attitudes and a heated debate in Sweden (Cinque 2008; Sjölander-Lindqvist et al. 2015). This debate seems reinforced by a more rapid change of attitudes in areas housing the increasing wolf population compared to areas with few wolves (Eriksson et al 2015). Paradoxically, the efforts to restore the wolf population and associated ecosystem services are provoking fear and antipathy about the impacts that these animals have or may have on human livelihoods and well-being (Shivak 2014). As a consequence, the role of human emotions has gained attention in governance and management of wolves (Bruskotter et al 2014; Jacobs 2012; Frank et al 2015; Manfredo 2008). Studies show that these large carnivores trigger interest and joy, as well as anger and fear (Treves et al. 2013; Jacobs et al. 2014). So far, the public's fear have received most attention, primarily in descriptions of the prevalence of fear (e.g. Bisi et al. 2007; Ericsson et al. 2010; Røskaft et al. 2003), and in analyses of fear, as a predictor of attitudes towards largecarnivore policy, decision-making, and implementation of management strategies (Hudenko 2012; Johansson et al. 2012a; Prokop and Fančovičová 2010; Slagle et al. 2012).

The wolf population in Scandinavia has increased from only four individuals in the early 1980s to about 430 in 2015/2016, 
with 340 individuals based in Sweden (Wabakken et al. 2016). Although the prevalence of fear does not necessarily correspond with the estimated risk of attacks by large carnivores (Linnell et al. 2003; Swenson et al. 1999), the increased number of wolves causes increased fear among the public (Ericsson et al 2013). Despite the extremely rare risk of attacks, there is an increasing trend in attacks all over Europe, correlating with the increasing number of people engaging in outdoor leisure activities. Seasonally, most of these attacks occur between late spring and early autumn, when people more frequently pursue outdoor activities (Penteriani et al. 2016). Since fear is a source of stress impacting on people's well-being and health, it has become increasingly important to take into consideration in wildlife management. Hence in order to allocate management resources in an efficient way, the antecedents of fear need to be understood and how they may differ between people; this would allow development of policy and management interventions likely to tap into the appropriate psychological constructs (Johansson and Karlsson 2011).

This study analyses antecedents of self-reported fear of wolf in a national sample of people living in Sweden. We test for differences in the structure of antecedents of self-reported feeling of fear between people who live at different geographical distances from areas with wolf presence, and between people with differing standpoint on protected nature areas.

\section{Antecedents of fear of large carnivores}

The emotion of fear is a fundamental human response and is as other emotions considered to include a subjective experience (feeling), physiological reactions, and behavioural expression (Lang 1984). Some psychologists also include other components of emotion, such as appraisal (Scherer 2001) and action readiness/tendencies (Frijda et al. 1989; Flykt 2006). In studies on fear of large carnivores, it is generally the subjective experience of fear, i.e. the feeling that is focused, usually captured by means of self-reports (Jacobs et al. 2012; Johansson et al. 2016).

According to appraisal theory, emotions are elicited and differentiated by the subjective interpretation of the personal significance of events. In this perspective, the individual's appraisal process is the key to understand a person's feeling of fear (Scherer 2001).

Human fear of animals seems to have two major groups of determinants that may influence the individual's appraisal of a potential large carnivore encounter, and ultimately, the experience of fear. The first encompasses human biological dispositions, e.g. individual personality traits and the degree of stimulus exposure needed to elicit a fear response, while the second group covers experiential factors including affective and cognitive learning experiences (Armfield 2006). The sparse literature on fear of large carnivores supports both the presence of biological factors via natural selection (Prokop and Fančovičová 2010), and direct and indirect learning experiences in childhood (Prokop et al. 2011) and adulthood (Røskaft et al. 2003).

Johansson et al. (2012b) proposed the FearSEM model as a framework to describe the appraisal in self-reported fear of wolf and brown bear. The FearSEM model combines theory on human-environment interaction (Küller 1991) and appraisal theory (e.g. Leventhal and Scherer 1987). At a low level of appraisal, fear responses to large carnivores are thought to be elicited more or less automatically by trigger stimuli, such as responses of evolutionarily old fear-driven neural circuits (e.g. LeDoux 1996; Öhman and Mineka 2001; Panksepp 1996). With more elaborate appraisal, the fear responses would also vary with the activity at hand, the perception of the environmental and social contexts, and individual factors (e.g. sociodemographic background, experiences, and personality). In a series of experimental studies, Flykt et al. (2013) concluded that self-reported fear of wolves most probably results from appraisal at an elaborated level, implying that the appraisal process is highly dependent on cognitive elaboration, and thereby stressing the relevance of the individual's interpretation of the environmental and social context to understand antecedents of fear of wolf.

As for the appraisal of the environmental context, empirical applications of the FearSEM model suggest that fear of wolves is associated with factors specified by the cognitive vulnerability model of animal fear (Armfield 2006, 2007), that is a relatively high degree of perceived danger, unpredictability of the animal's movement (i.e. uncertainty about the animal approaching or attempting to attack the person), and uncontrollability (i.e. the person's lack of control when responding to an encounter with an animal; Johansson and Karlsson 2011; Johansson et al. 2012b). These studies also points to an indirect effect of the appraisal of the animal species via the social context on self-reported fear of wolf, as well as a direct effect of the social context, operationalised as social trust according to the salient-value-similarity model (Cvetkovich and Winter 2003). Social trust describes the willingness to rely on those who are formally responsible for developing policies and taking measures (Cvetkovich and Winter 2003). Judgement of trust relies on heuristics (Cvetkovich and Winter 2007), including the similarity between oneself and the one to be trusted, e.g. shared values (Balliet and Van Lange 2013), and positive affect of the person to be trusted (Schoorman et al. 2007). In the FearSEM model, high ratings on the cognitive vulnerability items were associated with low ratings on social trust. Low social trust was in turn associated with higher self-reported fear. Zajac et al. (2012) confirm the association between salient-value-similarity, social trust, and the perception of risk of black bears (including fear of encounters). The study by Johansson et al. (2012b) has some limitations with regard to the possibilities for generalising the FearSEM model to a wider population: the participants had a relatively high mean age (53 years) and all 
lived in rural areas with documented problems regarding wolves or brown bear.

\section{Geographical location and standpoint on protected nature}

The wolf population in Sweden is primarily located in the southcentral part of the country. The role of people's geographical location in relation to wolf territories in shaping fear is a matter of debate. People living in areas of large carnivores have been reported to be less afraid than people outside these areas (Ericsson and Heberlein 2003a; Røskaft et al. 2003). At the time of these studies, the Scandinavian wolf population inhabited few and newly established territories (Wabakken et al. 2004). Recent studies indicate greater self-reported fear among people who are actually at risk, i.e. those who live within carnivore areas (Ericsson et al. 2010; Frank et al. 2015). Whether the divide in emotional responses and attitudes to wolves is a matter of proximity to the animals or an expression of a gap between urban and rural perspectives is debated (Dressel et al. 2014; Eriksson et al. 2015; Skogen and Krange 2003).

The public in western hemisphere societies are showing a tendency to transpose from utilitarianism to mutualism in response to increased welfare, including increase in education levels and urbanisation (Teel and Manfredo 2009). In Sweden, rural residents spend on average more time in the outdoors than urban citizens (Ericsson and Heberlein 2003b; Heberlein and Ericsson 2005; Fredman and Sandell 2009; Ljung et al. 2015). Previous studies show that there are significant regional differences in the presence of utilitarian perspectives based on learning about, for example, nature and wildlife from direct experiences, and mutualist perspective based on social interaction.

The public's relationship to nature has also been addressed by concepts such as ecological world view and environmental value orientation (Dunlap et al. 2000; Stern et al. 1995). Although Swedes generally report a strong ecological worldview (Widegren 1998; Wurzinger and Johansson 2006), differences in environmental value orientations may be found between different stakeholder groups, managers, and researchers. Stern and Dietz (1994) distinguished between egoistic environmental value orientation based on beliefs about the effect that environmental destruction may have on the individual, a social-altruistic (anthropocentric) orientation based on human benefits or human goals, and a biospheric (biocentric) orientation centred on the intrinsic value of the natural environment (see also Schultz 2001). In a study of the attitudes towards protected nature among the public in Sweden, Fredman and Sandell (2009) show that the people living close to areas with a high proportion of protected areas has a more utilitarian view on the use of the areas compared to those living on a distant. In general, this group is more supportive of social motives for protection than biological reasons and also more eager to accept commercial activities in the protected areas. A significantly higher proportion of the people in these areas are also more negative to the establishment of more protected areas. An increasing degree of urbanisation seems to reinforce the differences in values and attitudes between rural and urban areas due to social marginalisation and perceived lack of influence over large-carnivore policy and management (Eriksson et al. 2015). However, Sponarski et al. (2013) argued that the population in rural communities nowadays is heterogeneous. In a rural community, people could be divided into three clusters according to their attitude towards wolves. One group was slightly negative and were in favour of killing wolves, a second group had mixed feelings towards wolves, and a third group were not afraid of wolves, were not in favour of killing wolves, and thought that wolves should be maintained for future generations. Similarly, people in large-carnivore areas in Sweden representing different stakeholder groups differ in self-reported fear of wolves; in particular, environmental conservation organisations score lower on fear-related variables than other groups (Johansson and Karlsson 2011).

Bjerke and Kaltenborn (1991) compared the attitudes of sheep farmers, wildlife managers, and research biologists and found a positive association between biocentric motives and positive attitudes towards large carnivores and between anthropocentric motives and negative attitudes. The research biologist and managers were more positive towards large carnivores compared to sheep farmers. Sagør and Aasetre (1996) identified a similar difference between sheep farmers and managers of environmental conservation agencies, contributing to distrust. More than $80 \%$ of the farmers distrusted the official numbers of carnivore numbers, suspecting them of being too low and manipulated by the environmental authorities. In a frame analysis in Italy, Vitali (2014) reported that the perspectives of administrators and policy-makers, on the intrinsic value of the wolf, permeated the dominating frame, while the competing frame, confined largely to rural respondents, claimed that human activities should be the first priority within conservation policy. It has been suggested that the relationship between Scandinavians who live in large-carnivore areas and the managing authorities may be inflated by diverging values related to protection of nature corresponding to a utilitarian/ mutualist divide or a more anthropocentric vs ecocentric or biocentric view on nature (Ericsson and Heberlein 2003a, 2003b; Skogen and Krange 2003; Skogen and Thrane 2007; Skogen et al. 2008; Blekesaune and Rønningen 2010). Moreover, large carnivores, and in particular, wolves, play an important symbolic role in the social construction of local community because of their representation of urban power over rural areas (Skogen and Krange 2003; for a similar view on brown bears, see Blekesaune and Rønningen 2010). Thus, people's view on 
protected nature may have implications for the appraisal of the wolf itself.

\section{Aims and hypotheses}

This study aims to test the FearSEM model on antecedents of self-reported fear of wolf in a sample of the Swedish population. We also test for differences in the structure of antecedents of self-reported fear (i) between people who live in geographical locations with and without presence of wolves, (ii) between people who live in the administrative centre and periphery of counties with wolf presence, and (iii) between people with differing views on the importance of protected nature. In line with the FearSEM model, it is expected that self-reported fear:

$\left(\mathrm{H}_{1}\right)$ would be positively associated with the appraisal of wolf in terms of cognitive vulnerability model variables $\left(\mathrm{H}_{2}\right)$ would be negatively associated with social trust in the authorities responsible for large-carnivore policy and management

$\left(\mathrm{H}_{3}\right)$ a high level of cognitive vulnerability would be negatively associated with social trust

Following previous research on differing levels of selfreported fear among people who live within and outside wolf territories, as well as research suggesting value differences between different groups in the population, we expected that the pattern of the studied antecedents of self-reported fear would differ

$\left(\mathrm{H}_{4}\right)$ between people at different geographical distance from wolf areas

$\left(\mathrm{H}_{5}\right)$ between people who live in the administrative centre and periphery of wolf areas

$\left(\mathrm{H}_{6}\right)$ between people with different standpoints on the importance of protected nature areas

\section{Method}

\section{Sample}

We report data from a postal survey using up to four contacts (Dillman et al. 2009). In the surveys, we used a two-tiered sample design with data collected in national and regional questionnaire surveys on public perception of wildlife and nature. The national sample $(n=545)$ was a proportional sample of the Swedish population aged 16-65 (51.7\% female, $M_{\text {age }}=44.3$, corresponding to a response rate of $44 \%$ ). This national sample was randomly selected from the official Swedish population register and hence represents the Swedish population as a whole (Adresskälla SPAR, 17194 Solna). The regional sample was set up in order to capture variation in terms of rurality and experience of large carnivores. In four Swedish counties with established wolf territories (Dalarna, Gävleborg, Värmland and Örebro) and one with occasional presence of wolves (Kronoberg), data was collected in five municipalities per county with different degree of rurality, i.e. in total, 25 municipalities. The response rates varied from 41 (Grums, Värmland County) to $62 \%$ (Nordanstig, Gävleborg County). Included in this regional sample was also those respondents from the national sample that lived in the selected 25 municipalities $(n=50)$, resulting in a regional sample of $n=1,892(50.6 \%$ female, $M_{\text {age }}=46.2$ ). These 50 respondents were kept within the national sample for analyses on the national level in order not to violate the representation of the Swedish population. In the preoperational analyses in which all respondents were included, they are only represented once, resulting in a joint sample of $n=2,387$ (Fig. 1).

\section{Instruments}

Most of the questionnaire was based on previously published self-report measurements. The self-reported fear of wolf was measured by the questions "Are you afraid that wolves may attack people?" and "Are you afraid that wolves may attack pets or livestock?" Both items were answered using a 10-point scale ranging from (1) never to (10) always. These two groups of objects of fear have previously been shown to be highly correlated and the averaged responses were transformed to match the previously used $10-\mathrm{cm}$ scale (Johansson et al. $2012 b)$. The two items showed satisfactory internal reliability $(\alpha=0.783)$ and an index was computed as the average value for each individual. In analogy with Johansson et al. (2012b), this index was classified into seven categories representing verbal descriptions: never $(0-0.25)$, very seldom $(0.25-$ 1.25), seldom (1.25-3.25), sometimes (3.25-6.25), rather often (6.25-8.25), often (8.25-9.75) and always (9.75-10.00; Johansson et al. 2012b; Frank et al. 2015).

The appraisal of wolves was captured by the cognitive vulnerability model (CVM), using a 6-item version of the instrument (italics indicate reversed coding): (1) I think that the movement of wolves is impossible to understand in advance (Move), (2) I believe that if I came close to a wolf I would be harmed (Close), (3) I believe that I would be able to deal effectively with a wolf by myself if encountered (Deal), (4) I find wolves to be predictable in their movements (Predict), (5) I do not believe wolves could be dangerous to me (Danger), and (6) If a wolf came nearby I would probably not feel in control (Control). The responses were given on a 5 -point scale $(1=$ completely disagree to $5=$ completely agree; Armfield and Mattiske 1996; Johansson and Karlsson 2011; Johansson et al. 2012b).

Social trust was assessed by three items presented as statements: "I trust that the Environmental Protection Agency (EPA) / the County Administrative Board (CAB) / the Government manages the wolf populations with consideration to people who live in wolf areas" and derived 

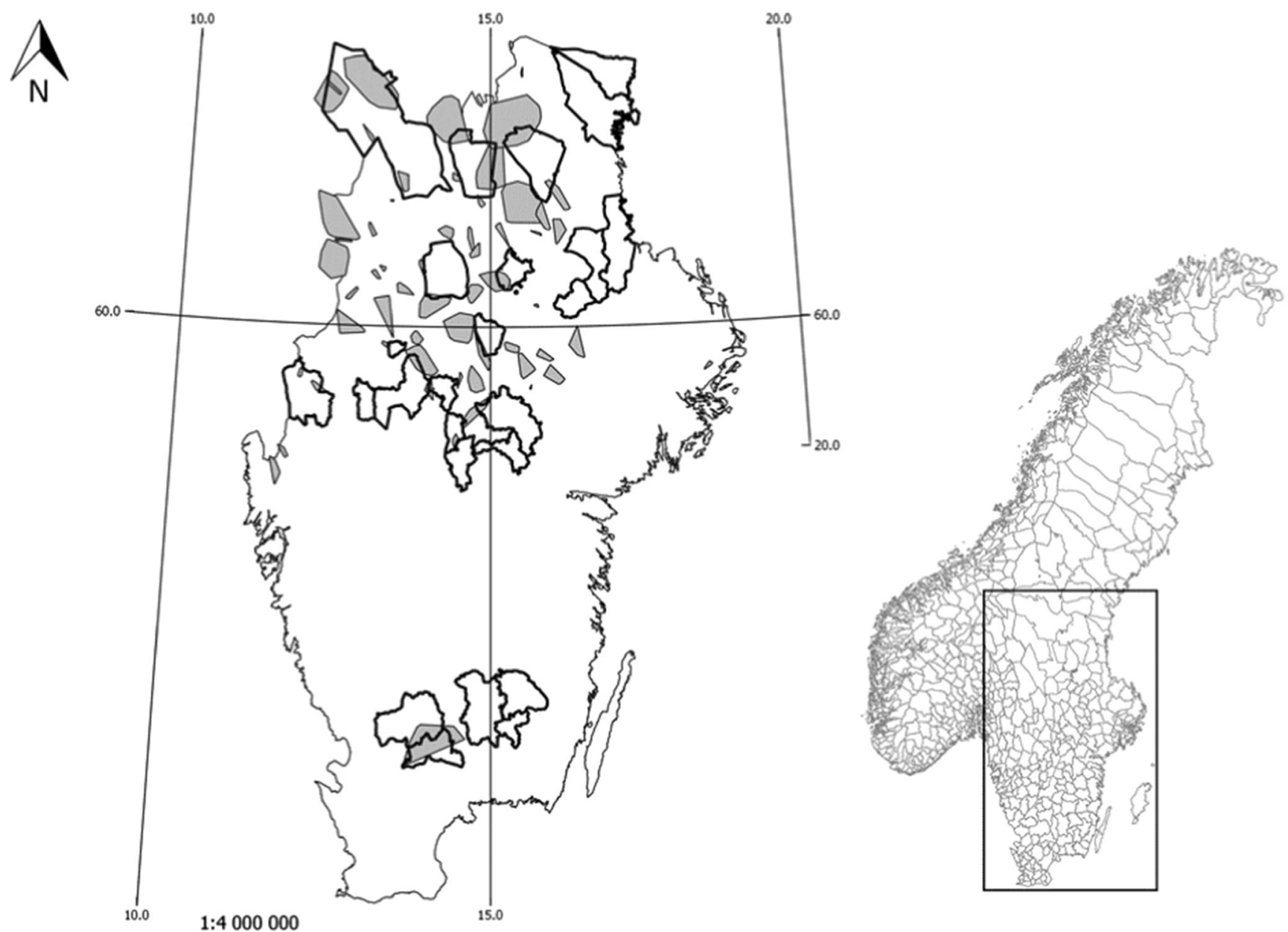

Fig. 1 Map of Sweden from the county of Dalarna in central Sweden to the county of Skåne in the south. Shaded polygons occupied confirmed wolf territories 2012, open polygons municipalities in the count sample

from the Salient-Value-Similarity model (Winter and Knap 2001; Johansson et al. 2012b). The responses were given on a 5 -point scale $(1=$ completely disagree to $5=$ completely agree).

The geographical location, i.e. five municipalities in each county, was derived from interviews with responsible officers in the five selected counties (Värmland, Dalarna, Örebro, Gävleborg and Kronoberg) and based on the parameters (i) urban centre, (ii) municipality with established wolf territory, (iii) municipality without established wolf territory and (iv) rural municipality.

Standpoint on protected nature was assessed by the question "What do you in general think about natureprotected areas" followed by six statements: nice places for recreation, important for biodiversity, relaxing environments, scenic environments, culturally interesting and important for future. The responses were given on a 5point scale $(1=$ completely disagree to $5=$ completely agree; Fredman and Sandell 2009).

\section{Data processing}

Preoperational statistical tests, e.g. principal component analysis, tests of internal reliability with Cronbach's alpha $(\alpha)$ and testing the measurement model, were carried out with the maximum number of respondents, i.e. the joint sample $(n=2,387)$. The internal drop-out varied between 1.76 and $3.27 \%$. Missing data was replaced with mean values for the total sample.

Five sets of subsamples to test the model in was based on the binary variables gender, age (dichotomised into younger or older than the median), education (no university vs. university), closeness to administrative centre of wolf areas (dichotomised into centre and periphery) and standpoint on protected nature. Principal component analysis showed that the six items measuring standpoint on nature protection formed one single factor (Table 1) with $64 \%$ of the variance explained $(\mathrm{KMO}=0.884$, Bartlett's test of sphericity $p<0.001)$ and had high internal reliability $(\alpha=0.89)$. One 
Table 1 Factor loadings for standpoint on protected nature

\begin{tabular}{ll}
\hline Item & Factor loadings \\
\hline Scenic environments & 0.84 \\
Relaxing environments & 0.84 \\
Important for future generations & 0.83 \\
Important for biodiversity & 0.78 \\
Nice places for recreation & 0.78 \\
Culturally interesting & 0.74 \\
\hline
\end{tabular}

All respondents $(n=2,387)$

factor was therefore calculated as the average of the six items for each respondent. The sample was then split into three groups of approximately the same size, representing low/ medium (1.00-3.99), high (4.00-4.65) and very high (4.67$5.00)$ levels of perceived importance of nature protection.

A two-step approach was used to test the structural model corresponding to the hypothetical model of self-reported fear of wolves (Hair et al. 2006). In the first step, a measurement model was tested to ensure that the manifest variables loaded satisfactorily on their respective latent variables. Next, possible causal relationships were tested in a structural model using maximum likelihood estimations for regression weights. Two indices of how well the model fitted the data were used: (a) comparative fit index, CFI, which indicates how well the covariance of the data is captured; a value $>0.90$ is acceptable (Bagozzi and Yi 1988), and (b) root mean square error of approximation, RMSEA, which is the discrepancy per degree of freedom for the model; values $<0.06$ indicate close fit to the data (Hu and Bentler 1995) and <0.095 acceptable fit (Bagozzi and Yi 1988). RMSEA is presented with a $90 \%$ confidence interval $(\mathrm{CI}) . \chi^{2}$ tests between the sample covariance matrix and the estimated covariance matrix, commonly used as an indicator of fit between data and the model, were not considered in this case due to the large number of cases. Construct reliabilities for the latent variables were calculated in accordance with Bagozzi and Yi (1988), where $>0.60$ is acceptable reliability.

\section{Results}

\section{Initial model testing}

The manifest variables chosen for the measurement model were satisfactorily correlated in a way that indicated that the model would fit the data (Table 2). The outcome variable selfreported fear was correlated with all other variables, but to different degrees. The six items measuring the appraisal of wolves (CVM) were correlated to a higher degree to each other than with items measuring social trust. Consistently, the three items measuring social trust were highly correlated, with weak correlations to the CVM items.

A measurement model was set up and tested. In the model, the two latent variables, CVM and social trust, and the manifest variable, fear, were proposed to correlate with each other. Error variables of the six items measuring CVM were also allowed to correlate if the correlation increased the model fit. All loadings of the measured variables on the latent constructs were highly statistically significant, and the construct reliabilities and variances explained were satisfactory (Table 3). The measurement model corresponded well with data: $\mathrm{CFI}=0.979$, RMSEA 0.062 (95 \% CI 0.055-0.069). Consequently, all manifest and latent constructs were retained and a structural model with hypothesised pathways arranged (Fig. 2).

\section{Moderating effects of geographical location}

The proposed model showed good fit with both the national and the regional sample, but with partly differing associations between variables (Table 4). In the national sample, the variation in self-reported fear was influenced directly, and positively, by CVM (pathway 2, P2) and negatively by social trust (P3) without any indirect effects from CVM via social trust (P1). The standardised regression weights in Table 4 indicate that the strength of the influence, i.e. the direct effect of CVM on fear, was 0.52 . In the regional sample, fear was predicted directly by CVM (P2) and social trust (P3), but also indirectly by CVM via social trust (P1), resulting in a total effect of 0.58 for CVM on fear. In both samples, a fairly large part of the variation in fear was explained by the model (see $R^{2}$ in Table 4).

Tests in subsamples showed that the model was also consistent over socio-demographic groups. However, in the national sample, CVM and social trust were stronger predictors for fear among older respondents than among younger. The differences in the pathway regression weights between older and younger respondents were statistically significant for P2 $(z=2.70, p<0.01)$ but not for P3 $(z=0.95, p=0.343)$. In the regional sample, social trust had a significant larger impact on fear among women than among men (P3 $z=2.75$, $p<0.01)$. Also, among older respondents as compared to younger respondents, CVM had a stronger direct effect on fear (P2 $z=2.44, p<0.05)$, and social trust had a lower effect on fear (P3 $z=3.31, p<0.001)$. No other differences were found between the socio-demographic groups.

\section{Moderating effects of closeness to administrative centre}

Respondents in the regional sample who lived close to an administrative centre differed from those who lived in the periphery (Table 5). In the latter group, we found, in addition to direct effects of CVM and social trust on fear (P2 and P3), an indirect effect of CVM on fear via social trust. This is similar to the difference identified above between 
Table 2 Pearson's product moment correlations between manifest variables proposed for the model

\begin{tabular}{|c|c|c|c|c|c|c|c|c|c|}
\hline & 1 & 2 & 3 & 4 & 5 & 6 & 7 & 8 & 9 \\
\hline \multicolumn{10}{|l|}{1 Fear } \\
\hline 2 Move & $0.14 * *$ & & & & & & & & \\
\hline 3 Close & $0.50 * *$ & $\underline{0.29 * *}$ & & & & & & & \\
\hline 4 Deal & $0.31 * *$ & $0 . \underline{28 * *}$ & $\underline{0.47 * *}$ & & & & & & \\
\hline 5 Predict & $0.19 * *$ & $\underline{0.46 * *}$ & $\underline{0.27 * *}$ & $\underline{0.55 * *}$ & & & & & \\
\hline 6 Danger & $0.50 * *$ & $0.17 * *$ & $\underline{0.62 * *}$ & $\underline{0.52 * *}$ & $0 . \underline{36 * *}$ & & & & \\
\hline 7 Control & $0.34 * *$ & $\underline{0.33 * *}$ & $\underline{0.52 * *}$ & $\underline{0.54 * *}$ & $\underline{0.31 * *}$ & $\underline{0.39 * *}$ & & & \\
\hline 8 Trust in $\mathrm{CAB}$ & $-0.23^{* *}$ & $0.09 * *$ & $-0.06^{* *}$ & -0.02 & -0.01 & $-0.18 * *$ & 0.02 & & \\
\hline 9 Trust in EPA & $-0.28 * *$ & $0.07 * *$ & $-0.07 * *$ & -0.01 & -0.00 & $-0.18 * *$ & 0.02 & $\underline{0.82 * *}$ & \\
\hline 10 Trust in Government & $-0.13^{* *}$ & $0.06^{* *}$ & 0.04 & 0.04 & -0.01 & $-0.07 * *$ & $0.05^{*}$ & $0.70 * *$ & $0.69 * *$ \\
\hline
\end{tabular}

Relationships between variables that initially were hypothesised to measure the same latent variable are underlined. All respondents $(n=2,387)$

$* p<0.05 ; * *<0.01$

the national and regional samples. No differences was found between periphery and centre in strength of regression weights for P2 or P3.

\section{Moderating effects of standpoint on protected nature}

Standpoint on protected nature had a moderating effect in both samples. In the national sample, the impact of social trust on fear (P3) decreased with increasing values for standpoint on protected nature, resulting in no impact among those with the highest values, i.e. those supposedly holding similar values as the authorities (Table 6). Only CVM predicted fear (P2) in the group of respondents with very high ratings for standpoint on protected nature. The variation in fear was explained to almost the same the degree $\left(R^{2}=0.26\right)$ as among those with lower values on

Table 3 Loading of the manifest indicators on their respective latent variable

\begin{tabular}{lll}
\hline & CVM & Social trust \\
\hline Fear & 0.87 & \\
Close & 0.86 & \\
Control & 0.62 & \\
Deal & 0.61 & \\
Predict & 0.43 & \\
Move & 0.35 & 0.91 \\
Trust in EPA & & 0.90 \\
Trust in CAB & & 0.76 \\
Trust in Government & & 0.86 \\
Construct reliability & 0.66 & 74 \\
Variance explained, \% & 43 & \\
\hline
\end{tabular}

Construct reliability and variance explained. All loadings (standardised regression weights) were statistically significant $(p<0.001)$. All respondents $(n=2,387)$ protected nature $\left(R^{2}=0.28\right.$ and $\left.R^{2}=0.31\right)$. The previous observed lack of influence of CVM on social trust in the national sample remained for all three levels. In the regional sample, CVM was expected to influence social trust (P1) as shown above, but this could only be seen among those with high or very high standpoint on protected nature. Among respondents who assessed protected nature to be of low or intermediate importance, there were only direct effects of CVM (P2) and social trust (P3); i.e. social trust did not have a mediating effect. Also, the variance explained in fear was relatively lower than for those with high or very high standpoint though the model fit was as good. Regression weights and variance explained were in the same range as for the group with low/medium standpoint on protected nature in the national sample.

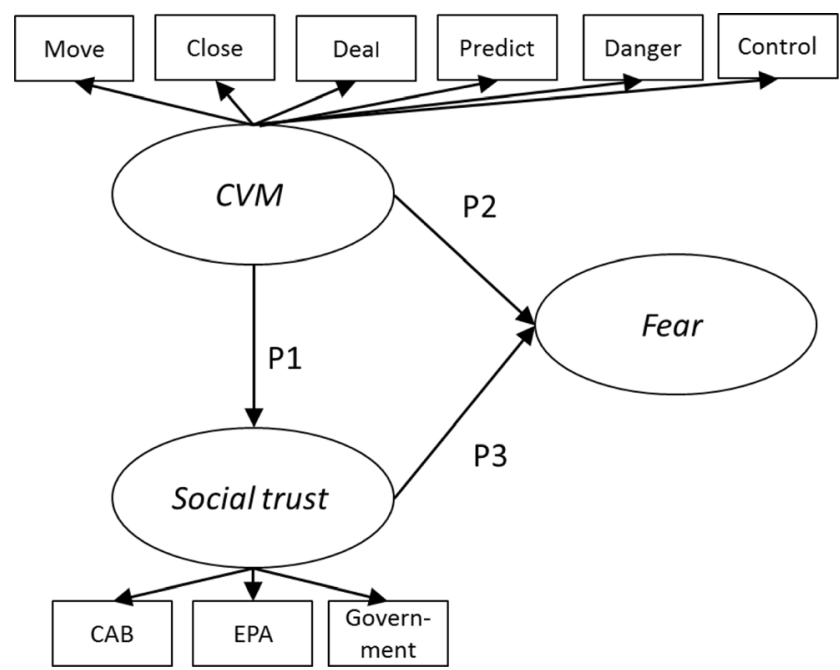

Fig. 2 Structural model used for testing the influence of possible moderating variables 
Table 4 Standardised regression weights and model fit for the tested samples and sociodemographic subsamples

\begin{tabular}{|c|c|c|c|c|c|c|c|}
\hline \multicolumn{8}{|l|}{ National sample } \\
\hline & & \multicolumn{3}{|c|}{ Standardised regression weights } & Fear & \multicolumn{2}{|c|}{ Model fit indices } \\
\hline & $n$ & $\mathrm{P} 1$ & $\mathrm{P} 2$ & P3 & $R^{2}$ & CFI & RMSEA $(90 \% \mathrm{CI})$ \\
\hline Total & 545 & n.s. & 0.52 & -0.17 & 0.31 & 0.98 & $0.06(0.04$ to 0.07$)$ \\
\hline \multicolumn{8}{|l|}{ Gender } \\
\hline Women & 282 & n.s. & 0.52 & -0.15 & 0.31 & 0.98 & $0.05(0.03$ to 0.08$)$ \\
\hline Men & 263 & n.s. & 0.51 & -0.21 & 0.30 & 0.98 & $0.06(0.04$ to 0.09$)$ \\
\hline \multicolumn{8}{|l|}{ Age } \\
\hline$\leq 46$ & 261 & n.s. & 0.42 & -0.12 & 0.19 & 0.98 & $0.06(0.03$ to 0.08$)$ \\
\hline$>46$ & 284 & n.s. & 0.60 & -0.21 & 0.41 & 0.98 & $0.06(0.04$ to 0.09$)$ \\
\hline \multicolumn{8}{|l|}{ Education } \\
\hline No university & 319 & n.s. & 0.53 & -0.16 & 0.30 & 0.99 & $0.03(0.00$ to 0.06$)$ \\
\hline University & 226 & n.s. & 0.50 & -0.17 & 0.29 & 0.97 & $0.08(0.06$ to 0.11$)$ \\
\hline \multicolumn{8}{|l|}{ Regional sample } \\
\hline & & \multicolumn{3}{|c|}{ Standardised regression weights } & Fear & \multicolumn{2}{|c|}{ Model fit indices } \\
\hline & $n$ & $\mathrm{P} 1$ & $\mathrm{P} 2$ & P3 & $R^{2}$ & CFI & RMSEA $(90 \% \mathrm{CI})$ \\
\hline Total & 1892 & -0.14 & 0.55 & -0.21 & 0.38 & 0.98 & $0.06(0.05$ to 0.07$)$ \\
\hline \multicolumn{8}{|l|}{ Gender } \\
\hline Women & 957 & -0.19 & 0.61 & -0.15 & 0.43 & 0.98 & $0.06(0.05$ to 0.07$)$ \\
\hline Men & 935 & -0.14 & 0.47 & -0.27 & 0.32 & 0.97 & 0.07 (0.06 to 0.08$)$ \\
\hline \multicolumn{8}{|l|}{ Age } \\
\hline$\leq 46$ & 785 & -0.12 & 0.53 & -0.26 & 0.39 & 0.97 & $0.07(0.06$ to 0.08$)$ \\
\hline$>46$ & 1107 & -0.16 & 0.57 & -0.18 & 0.38 & 0.99 & 0.05 (0.04 to 0.07$)$ \\
\hline \multicolumn{8}{|l|}{ Education } \\
\hline No university & 1383 & -0.14 & 0.55 & -0.19 & 0.37 & 0.98 & $0.06(0.05$ to 0.07$)$ \\
\hline University & 509 & -0.12 & 0.53 & -0.25 & 0.37 & 0.97 & 0.07 (0.06 to 0.09$)$ \\
\hline
\end{tabular}

\section{Discussion}

This study supports the idea that self-reported fear of wolves is an outcome of emotional appraisal at a cognitively elaborated level among the population in Sweden (Johansson et al. 2012b; Flykt et al. 2013). Our analyses of national and regional samples confirm the relevancy of the identified dual paths of antecedents of the feeling of fear of wolves. One path includes the appraisal of the environmental context, in this case the appraisal operationalised as cognitive vulnerability, the perceived danger in a potential wolf encounter, unpredictability of the animal's behaviour and the uncontrollability of the individual's own reaction. The other path encompasses the appraisal of the social context around largecarnivore management, here operationalised as social trust in the managing authorities. The indirect effect of cognitive vulnerability via social trust was partly confirmed; showing that high cognitive vulnerability in some groups was associated with low social trust and hence self-reported fear. These results lend support to our first three hypotheses and imply that public fear of wolves should be addressed both at an individual level, focusing on situations with potential encounters, and
Table 5 Standardised regression weights and model fit for distance from the respondents address to the closest administrative centre in wolf areas (periphery or centre)
Regional sample

\begin{tabular}{|c|c|c|c|c|c|c|c|}
\hline & \multirow[b]{2}{*}{$n^{\mathrm{a}}$} & \multicolumn{3}{|c|}{ Standardised regression weights } & \multirow{2}{*}{$\begin{array}{l}\text { Fear } \\
R^{2}\end{array}$} & \multicolumn{2}{|c|}{ Model fit indices } \\
\hline & & $\mathrm{P} 1$ & $\mathrm{P} 2$ & P3 & & CFI & RMSEA $(90 \% \mathrm{CI})$ \\
\hline Periphery & 1534 & -0.14 & 0.55 & -0.22 & 0.39 & 0.98 & $0.06(0.05$ to 0.07$)$ \\
\hline Centre & 275 & n.s. & 0.53 & -0.14 & 0.30 & 0.97 & $0.08(0.05$ to 0.10$)$ \\
\hline
\end{tabular}

${ }^{\mathrm{a}} n=83$ living in Borlänge were excluded since this is an urbanised area but without being the formal regional centre 
Table 6 Standardised regression weights and model fit for subsamples based on view of nature protection

\begin{tabular}{|c|c|c|c|c|c|c|c|}
\hline \multicolumn{8}{|l|}{ National sample } \\
\hline & \multirow[b]{2}{*}{$n$} & \multicolumn{3}{|c|}{ Standardised regression weights } & \multirow{2}{*}{$\begin{array}{l}\text { Fear } \\
R^{2}\end{array}$} & \multicolumn{2}{|c|}{ Model fit indices } \\
\hline & & $\mathrm{P} 1$ & $\mathrm{P} 2$ & P3 & & $\mathrm{CFI}$ & $\operatorname{RMSE}(90 \% \mathrm{CI})$ \\
\hline \multicolumn{8}{|c|}{ Standpoint on protected nature } \\
\hline Low/medium & 103 & n.s. & 0.48 & -0.22 & 0.28 & 1.00 & $0.00(.00$ to 0.06$)$ \\
\hline High & 199 & n.s. & 0.54 & -0.19 & 0.31 & 0.97 & $0.07(0.04$ to 0.10$)$ \\
\hline Very high & 243 & n.s. & 0.50 & n.s. & 0.26 & 0.99 & $0.05(0.01$ to 0.08$)$ \\
\hline \multicolumn{8}{|l|}{ Regional sample } \\
\hline & & \multicolumn{3}{|c|}{ Standardised regression weights } & Fear & \multicolumn{2}{|c|}{ Model fit indices } \\
\hline & $n$ & P1 & P2 & $\mathrm{P} 3$ & $R^{2}$ & CFI & RMSE $(90 \%$ CI) \\
\hline \multicolumn{8}{|c|}{ Standpoint on protected nature } \\
\hline Low/medium & 511 & n.s. & 0.44 & -0.16 & 0.23 & 0.98 & $0.07(0.05$ to 0.08$)$ \\
\hline High & 693 & -0.13 & 0.63 & -0.23 & 0.48 & 0.98 & $0.06(0.05$ to 0.08$)$ \\
\hline Very high & 687 & -0.13 & 0.54 & -0.21 & 0.37 & 0.98 & $0.06(0.04$ to 0.07$)$ \\
\hline
\end{tabular}

at a collective societal level by strengthening the trust between the public and authorities.

Our results also point to a moderating effect of geographical location on the structure of antecedents of fear of wolves. The effect of the environmental (animal-related) path was stronger the further away the respondents lived from areas with wolves, whereas the social (management-related) path was more important to self-reported fear among those who lived closer to the animals, confirming hypothesis four. This pattern was evident in the comparisons between the national sample and the regional sample, and in the comparison between respondents in the administrative centre (relatively urban) and peripheral areas (relatively rural) in the regional sample. This result may indicate that rural residents who are negatively affected by the presence of wolves perceive a lack in coping strategies facilitated by social support from managing authorities (Johansson and Frank 2015). This situation may thereby serve as a hotbed for mistrust, fuelling feelings of fear.

Similarly, the mediating role of social trust between cognitive vulnerability and self-reported fear could only be confirmed in the regional sample. In the more detailed comparison between those who lived in the regional administrative centre and those who lived in the regional periphery, this pattern was again repeated. The structure among respondents who live in the administrative centre was similar to that identified in the national sample. People who live relatively close to wolves, regardless of whether it is in large scale or small scale, seem to make a stronger connection between environmental (animal-related) and social (managementrelated) aspects of the presence of wolves in their feeling of fear. Taken together, these support hypothesis five and might indicate not only a national urban-rural divide (Skogen and Krange 2003; Ericsson and Heberlein 2003a, b), but also the presence of regional centre-periphery divide. Consequently, our results further nuance the rural heterogeneity hypothesis posed by Sponarski et al. (2013), by suggesting that more "urban" perspectives may not be evenly distributed in rural areas but, at least in Sweden, primarily present among people who live in the regional centres. Heterogeneity seems to follow a certain pattern, repeating the national pattern, indicating divides between local centre and local periphery. Such differences reflect discrepancies identified already in the 1980 s by Rokkan and Urwin (1983). At the same time, the results suggest that the Swedish rural population in wolf areas is not yet as heterogeneous as that identified in the USA (Sponarski et al. (2013), possibly because the Swedish municipalities are characterised by out-migration rather than in-migration.

Views on protected nature and wildlife have previously been shown to differ among Swedes (Fredman and Sandell 2009) and to affect human attitudes to large carnivores (Bjerke and Kaltenborn 1991; Sagør and Aasetre 1996). We expected that the pattern of the studied antecedents of self-reported fear would differ between people with different standpoint on protected nature. The major finding was that, in the national sample, people who assessed protected nature as being highly important did not seem to make any association between social trust and self-reported fear. This means that hypothesis six was only partly supported. One explanation might be that biologists and people representing managing authorities often seem to have a relatively stronger biocentric environmental value orientation, stressing the importance of conserving biotopes and species for their inherent value more than, for example, farmers and other rural residents (Bjerke and Kaltenborn 1999; Fredman and Sandell 2009; Lindström et al. 2006). Following the idea of the Salient-ValueSimilarity model of social trust, the respondents attributing highest importance to protected nature may assess the managing authorities' values to be more similar to their own, making trust less of an issue than the appraisal of the animal in this group. Blekesaune and Rønningen (2010) draw a similar 
conclusion concerning attitudes towards brown bears in Norway. Still, this linterpretation would need to be confirmed in further studies on social trust and large carnivore management.

One factor that might play into the moderating effects on self-reported fear of geographical location as well as stand point on protected nature areas is the role of personal experience of encountering wolves close to where one live (Johansson et al. 2012b). Another factor might be the dependency on different livelihoods between people who live in relatively more urban and rural areas (Fredman and Sandell 2009; Blekesaune and Rønningen 2010). The pattern of antecedents reported refers to a general feeling of fear of wolves rather than the feeling experienced at a specific encounter. The latter would be influenced by an additional number of specific situational factors. Such a situation would preferably be followed-up by a qualitative approach. In further quantitative approaches, it would be worthwhile to address people's views on nature by using established instruments to differentiate between egoistic, social-altruistic and biospheric value orientations (Johansson and Henningsson 2011; Schultz 2001). The sample size allowed feelings of fear to be analysed, but in further studies it would be interesting to use sub-samples to test differing structures of antecedents of fear also in relation to physiological and behavioural fear responses (Flykt et al. 2013).

\section{Conclusion and management implications}

Based on the results presented above, it is essential to take a holistic approach to the design and evaluation of policy and management measures by including both the individual level, focusing on situations with potential encounters and the collective societal level through the strengthening of trust between the public and authorities. However, while a number of measures to prevent human-wolf conflicts are currently tested and evaluated in Sweden and other countries, the role of social trust has not attracted sufficient attention among managing authorities. Since the current lack of trust in the large carnivore arena will interfere with the possibility of introducing management measures it is necessary to put more effort also into trust-building activities, such as collaborative engagement processes improving the clarity on key concerns; active conflict management, efforts to enhance mutual respect among involved actors and enhanced decision-making processes as well as the integration of relevant knowledge into deliberations and decisions (Sjölander-Lindqvist et al. 2015).

Acknowledgments This research was funded through Formas grant 250-2008-402 to Maria Johansson and 251-2011-117 to Camilla Sandström and via start-up grants from the Faculty of Forestry, SLU, to Göran Ericsson.

\section{Compliance with ethical standards}

Ethical statement The authors ensure that this research in all instances complies with the national ethical research guidelines in Sweden and those of the American Psychological Association.

Open Access This article is distributed under the terms of the Creative Commons Attribution 4.0 International License (http:// creativecommons.org/licenses/by/4.0/), which permits unrestricted use, distribution, and reproduction in any medium, provided you give appropriate credit to the original author(s) and the source, provide a link to the Creative Commons license, and indicate if changes were made.

\section{References}

Armfield JM (2006) Cognitive vulnerability: a model of the etiology of fear. Clin Psychol Rev 26:746-768

Armfield JM (2007) Manipulating perceptions of spider characteristics and predicted spider fear: evidence for the cognitive vulnerability model of the etiology of fear. J Anxiety Disord 21:691-703

Armfield JM, Mattiske JK (1996) Vulnerability representation: the role of perceived dangerousness, uncontrollability, unpredictability and disgustingness in spider fear. Behav Res Ther 34:899-909

Bagozzi RP, Yi Y (1988) On the evaluation of structural equation models. J Acad Mark Sci 16:74-94

Balliet D, Van Lange PAM (2013) Trust, conflict and cooperation: a metaanalysis. Psychol Bull 139:1090-1112

Bisi J, Kurki S, Svensberg M, Liukkonen T (2007) Human dimensions of wolf (Canis lupus) conflicts in Finland. Eur J Wildl Res 53:304-314

Bjerke T, Kaltenborn BP (1991) The relationship of ecocentric and anthropocentric motives to attitudes towards large carnivores. J Environ Psychol 19:415-421

Blekesaune A, Rønningen K (2010) Bears and fears: cultural capital, geography and attitudes towards large carnivores in Norway. Nor J Geol 64(4):185-198

Boitani, L. Linell. JDC (2016) Bringing large mammals back: large carnivores in Europe. In: Pereira, Henrique M., Navarro, Laetitia (Eds.) Rewilding European landscapes.Springer International Publishing, p. 227.

Bruskotter JT, Vucetich JA, Enzler S, Treves A, Nelson MP (2014) Removing protections for wolves and the future of the US Endangered Species Act (1973). Conserv Lett 7:401-407

Cinque S (2008) I vargens spår [In the wolf track]. Doctoral dissertation. University of Gothenburg, Gothenburg

Cvetkovich G, Winter PL (2003) Trust and social representations of the management of threatened and endangered species. Environ Behav 35:286-307

Cvetkovich G, Winter PL (2007) The what, how and when of social reliance and cooperative risk management. In: Siegrist M, Earle TC, Gutscher H (eds) Trust in cooperative risk management. Earthscan, London, pp 187-209

Dillman, D. et al. 2009. Internet, mail, and mixed-mode surveys: the tailored design method. Wiley

Dressel S, Sandström C, Ericsson G (2014) A meta-analysis of studies on attitudes toward bears and wolves across Europe 1976-2012. Conserv Biol 29:565-574

Dunlap RE, Van Liere KD, Mertig AG, Jones RE (2000) Measuring endorsement of the new ecological paradigm: a revised NEP scale. J Soc Issues 56:425-442 
Ericsson G, Heberlein TA (2003a) Attitudes of hunters, locals, and the general public in Sweden now that the wolves are back. Biol Conserv 111:149-159

Ericsson G, Heberlein TA (2003b) Hunters speak nature's language: a comparison of outdoor activities and attitudes toward wildlife among Swedish hunters and the general public. Eur J Wildl Res 48(supplement):301-308

Ericsson G, Sandström C, Kindberg J, Stoen O-G (2010) Om svenskars rädsla för stora rovdjur, älg och vildsvin. [On Swedes' fear of large carnivores, moose and wild boar]. Swedish University of Agricultural Sciences, Umeå, p 1

Ericsson G, Sandström C, Kagervall A, Johansson M (2013) Attityder till varg och vargförvaltning. Umeå, Swedish University of Agricultural Sciences

Eriksson M, Sandström C, Ericsson G (2015) Direct experience and attitude change towards bears and wolves. Wildl Biol 21:131-137

Flykt A (2006) Preparedness for action: responding to the snake in the grass. Am J Psychol 119:29-44

Flykt A, Johansson M, Karlsson J, Lindeberg S, Lipp O (2013) Fear of wolf and bear. Hum Dimens Wildl 18:416-443

Frank J, Johansson M, Flykt A (2015) Managing human fear of brown bear and wolf. Eur J Wildl Biol 21:122-130

Fredman P, Sandell K (2009) Protect, preserve, present. The Rike of tourism in Swedish national parks. In: Frost W, Hall Michael C (eds) Tourisms and national parks: international perspectives on development, histories and change. Routledge, London, pp 197-207

Frijda NH, Kuipers P, ter Schure E (1989) Relations among emotion, appraisal, and emotional action readiness. J Pers Soc Psychol 57: 212-228

Hair JF, Black B, Babin B, Anderson RE, Tatham RL (2006) Multivariate data analysis. Prentice-Hall, London

Heberlein T, Ericsson G (2005) Ties to the countryside: urban attitudes toward hunting, wildlife and wolves. Hum Dimens Wildl 10:213-227

$\mathrm{Hu}$ L-T, Bentler PM (1995) Evaluating model fit. In: Hoyle RH (ed) Structural equation modelling. Concept, issues, and applications. Sage, London

Hudenko HW (2012) Exploring the influence of emotion on human decision making in human-wildlife conflict. Hum Dimens Wildl 17: $16-28$

Jacobs MH (2012) Human emotions toward wildlife. Hum Dimens Wildl $17: 1-3$

Jacobs M, Vaske JJ, Dubois S, Fehres P (2014) More than fear: the role of emotions in acceptability of lethal control of wolves. Eur J Wildl Res 60:589-598

Johansson M, Frank J (2015) The impact of access to ultra-sonic device on human fear of wolves. Wildl Biol. doi:10.2981/wlb.00154

Johansson M, Henningsson M (2011) Social-psychological factors in public support for local biodiversity conservation. Soc Nat Resour 24:717-733

Johansson M, Karlsson J (2011) Subjective experience of fear and the cognitive interpretation of large carnivores. Hum Dimens Wildl 16: $15-29$

Johansson M, Sjöström M, Karlsson J, Brännlund R (2012a) Is human worry affecting public support of management and conservation of large carnivores? Soc Nat Resour 25:610-620

Johansson M, Karlsson J, Pedersen E, Flykt A (2012b) Factors governing human fear of brown bear and wolf. Hum Dimens Wildl 17:58-74

Johansson M, Ferreira I, Støen OG, Frank J, Flykt A (2016) Targeting human fear of large carnivores - many ideas but few known effects. Biol Conserv 201:261-269

Küller R (1991) Environmental assessment from a neuropsychological perspective. In: Gärling T, Evans GW (eds) Environment, cognition, and action. Oxford University Press, New York, pp 111-147

Lang PJ (1984) Cognition in emotion: concept and action. In: Izard CE, Kagan J, Zajonc RB (eds) Emotions, cognition, and behavior. Cambridge University Press, Cambridge, pp 192-226
LeDoux JE (1996) The emotional brain: the mysterious underpinnings of emotional life. Simon \& Schuster, New York

Leventhal H, Scherer K (1987) The relationship of emotion to cognition: a functional approach to a semantic controversy. Cognit Emotion 1: $3-28$

Lindström M, Johansson M, Herrman J, Jonsson O (2006) Attitudes towards the conservation of biological diversity. A case study in Kristianstad municipality, Sweden. J Environ Plan Manag 49:495-513

Linnell JDC, Solberg EJ, Brainerd S, Liberg O, Sand H, Wabakken P, Kojola I (2003) Is the fear of wolves justified? A Fennoscandian perspective. Acta Zool Lituanica 13:27-33

Ljung P, Riley S, Ericsson G (2015) Game meat consumption feeds urban support of traditional use of natural resources. Soc Nat Resour 28: 657-669

Manfredo MJ (2008) Who cares about wildlife? Social science concepts for exploring human-wildlife relationships and conservation issues. Springer, New York

Öhman A, Mineka S (2001) Fears, phobias, and preparedness: toward an evolved module of fear and fear learning. Psychol Rev 108:483-522

Panksepp J (1996) Affective neuroscience: a paradigm to study the animate circuits for human emotions. In: Kavanaugh RD, Zimmerberg B, Fein S (eds) Emotion: interdisciplinary perspectives. Lawrence Erlbaum Associates, Hillsdale, pp 29-60

Penteriani $\mathrm{V}$ et al (2016) Human behaviour can trigger large carnivore attacks in developed countries. Sci Rep 6:20552. doi:10.1038/srep20552

Prokop P, Fančovičová J (2010) Perceived body condition is associated with fear of a large carnivore predator in humans. Ann Zoo Fennici 47:417-425

Prokop P, Usak M, Erdogan M (2011) Good predators in bad stories: cross-cultural comparison of children's attitudes towards wolves. J Baltic Sci Educ 10:229-242

Rokkan S, Urwin DW (1983) Economy, territory, identity: politics of west European peripheries. SAGE Publications Ltd., London

Røskaft E, Bjerke T, Kaltenborn B, Linell JDC, Andersen R (2003) Patterns of self-reported fear towards large carnivores among the Norwegian public. Evol Hum Behav 24:184-198

Sagør JT, Aasetre J (1996) Forvaltere og bønder: kan de enes om bjørneforvaltningen? Norwegian University of Science and Technology, Centre for Environment and Development. SSMURapp 1(96):1-94

Scherer KR (2001) Appraisal considered as a process of multi-level sequential checking. In: Scherer KR, Schorr A, Johnstone T (eds) Appraisal processes in emotion: theory, methods, research. Oxford University Press, New York, pp 92-120

Schoorman FD, Mayer RC, Davis JH (2007) An integrative model of organizational trust: past, present and future. Acad Manage Rev 32:344-354

Schultz PW (2001) The structure of environmental concern: concern for self, other people, and the biosphere. J Environ Psychol 21:327-339

Shivak JA (2014) The predator paradox: ending the war with wolves, bears, cougars, and coyotes. Beacon Press, Boston

Sjölander-Lindqvist A, Johansson M, Sandström C (2015) Individual and collective responses to large carnivore management: the roles of trust, representation, knowledge spheres, communication and leadership. Wildl Biol 21:175-185

Skogen K, Krange O (2003) A wolf at the gate: the anti-carnivore alliance and the symbolic construction of community. Sociol Ruralis 43: 309-325

Skogen K, Thrane C (2007) Wolves in context: using survey data to situate attitudes within a wider cultural framework. Soc Nat Resour 21:17-33

Skogen K, Mauz I, Krange O (2008) Cry wolf! Narratives of wolf recovery in France and Norway. Rural Sociol 73:105-133 
Slagle K, Zajac R, Bruskotter J, Wilson R, Prange S (2012) Building tolerance for bears: a communications experiment. J Wildl Manage 77:863-869

Sponarski CC, Semeniuk C, Glikman JA, Bath AJ, Musiani M (2013) Heterogeneity among rural resident attitudes towards wolves. Hum Dimens Wildl 18:239-248

Stern PC, Dietz T (1994) The value basis of environmental concern. J Soc Issues 50:65-84

Stern PC, Dietz T, Guagnano GA (1995) The new ecological paradigm in social-psychological context. Environ Behav 27:723-753

Swenson JE, Sandegren F, Söderberg A, Heim M, Sørensen OJ, Bjärvall A, Franzén R, Wikan S, Wabakken P (1999) Interactions between brown bears and humans in Scandinavia. Biosph Conserv 2:1-9

Teel TL, Manfredo MJ (2009) Understanding the diversity of public interests in wildlife conservation. Conserv Biol 1:128-139

Treves A, Naughton-Treves L, Shelley V (2013) Longitudinal analysis of attitudes toward wolves. Conserv Biol 27:315-323

Vitali C (2014) A frame-analytical perspective on conflict between people and an expanding wolf Canis lupus population in central Italy. Oryx $48: 575-583$
Wabakken P, Aronson A, Sand H, Rønning H, Kojola I (2004) The wolf in Scandinavia: status report of the 2002-2003 winter. Høgskolen i Hedmark Viltskadecenter, Grimsö forskningsstation, Vilt-och fiskeriforskningen, Oulu

Wabakken, P., Svensson, L., Maartmann, E., Åkesson, M \& Flagstad, Ø. 2016. Bestandsovervåking av ulv vinteren 2015-2016. Bestandsstatus for store rovdyr i Skandinavia 1-2016. 49 s. Evenstad og Grimsö. Rovdata og Viltskadecenter, SLU

Widegren Ö (1998) The new environmental paradigm and personal norms. Environ Behav 30:75-100

Winter PL, Knap NE (2001) An exploration of recreation and management preferences related to threatened and endangered species. Pacific Southwest Station, USDA Forest Service, Riverside

Wurzinger S, Johansson M (2006) Environmental concern and knowledge of ecotourism among three groups of Swedish tourists. J Travel Res 45:217-226

Zajac RM, Bruskotter JT, Wilson RS, Prange S (2012) Learning to live with black bears: a psychological model of acceptance. J Wildl Manag 76:1331-1340 